\title{
ELECTION 2015: A MANIFESTO FOR THE DENTAL INDUSTRY
}

The British Dental Industry Association (BDIA) has launched a 'Dental Industry Manifesto' which sets out five key priorities for action in the dental sector for the next government. BDIA Executive Director, Tony Reed, explains: 'The industry believes that positive and focussed investment and support from government is vital to ensure the highest quality oral health outcomes for patients and an efficient and sustainable future for the provision of dentistry in the UK.'

The BDIA feel that by acting in the areas highlighted in the Manifesto a future government can significantly reduce the burden on the NHS by improving the nation's oral health, whilst also supporting dental professionals and fostering innovation. The Manifesto also builds on the recent initiative against counterfeit and non-compliant dental devices and instruments seeking full government funding for the Medical and Healthcare Products Regulatory Agency. It has been circulated to key opinion formers in the political parties and government departments, as well as to Ministers, MPs, senior civil servants and NHS England.

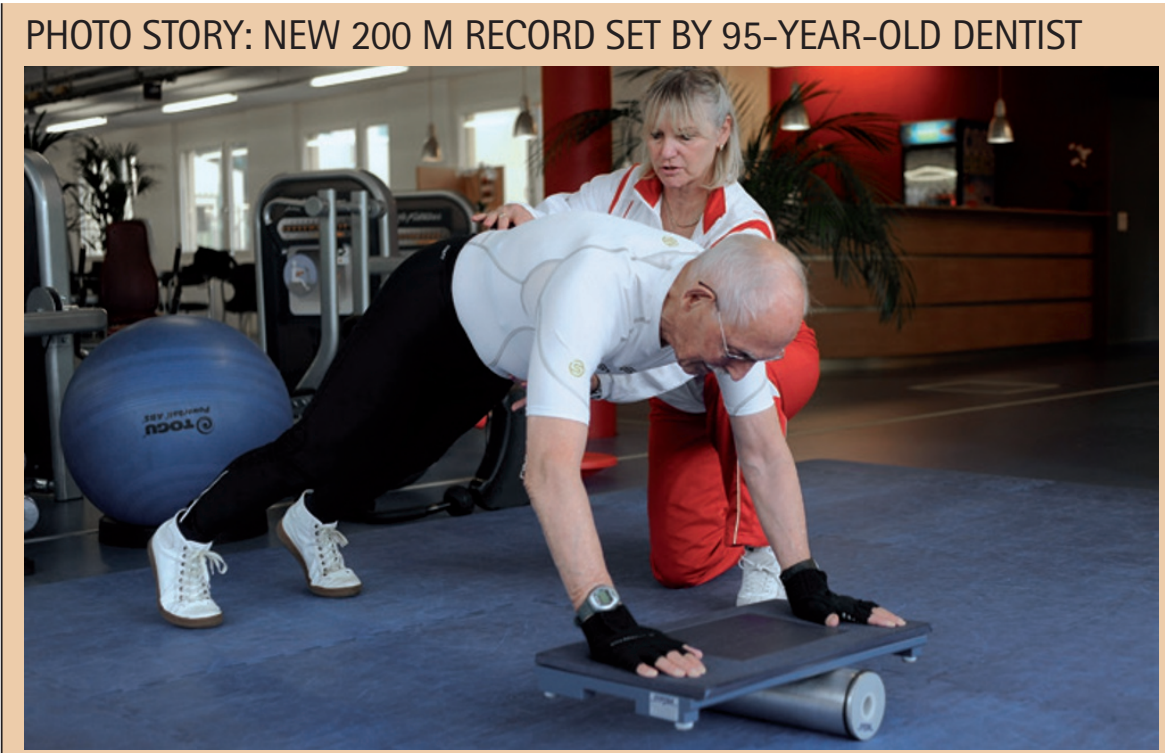

Retired dentist Dr Charles Eugster has broken the 200 metres indoor world record in the 'men aged 95+' category twice in two weeks. Eugster first set a new record at the indoor British Masters in London early in March of 55.48 seconds. He bettered this time to set a new record of 54.77 seconds at the European Masters Championships held in Torun, Poland on 27 March 2015. Eugster said,
'It shows that with a little training you can set records at any age! To set a World best at Lee Valley was a huge achievement, but to better it here today in Torun is, for me, remarkable. It proves that you can set yourself challenges and goals at any age and achieve them.' The 95-year-old, exdentist is also a competitive oarsman and bodybuilder.

\section{BDA 2015 CONFERENCE APP}

The BDA have launched a new app to help you manage your time at this year's British Dental Conference and Exhibition. The app will allow delegates to navigate the venue finding exhibitors, suppliers and sessions with ease using interactive maps of the hall and conference session venue. The entire conference programme is contained within the app and delegates can also select sessions they would like to attend to build their own personalised event diary. All the exclusive show offers are held in the app ensuring delegates don't miss out on special discounts, promotions and competitions. Delegates can also access Twitter and Facebook directly to interact and share their views. The app is available to download now via the Apple App Store or Google Play, search for 'BDA Conference 2015:

This year's British Dental Conference and Exhibition will take place from 7-9 May at the Manchester Central Convention. To register for your place visit www.bda.org/conference or call the registration team direct on 08701666625. 